دSCM T

Journal of Sustainable Construction

Materials and Technologies

\title{
Mechanical and Durability Performance of Self Compacting Concrete Containing Fly Ash and Metakaolin
}

\author{
Dr. Rizwan A. Khan* \\ Associate Professor, Department of Civil Engineering, Aligarh Muslim University Aligarh, UP ,India, 202002
}

Received August 14, 2016; accepted March 15, 2017

\begin{abstract}
This paper is concerned with Self compacting concrete (SCC) which is a highly flow-able, non-segregating concrete that can spread into place, fill the formwork and encapsulate the reinforcement without any need for vibration. The elimination of the need for compaction leads to better quality concrete and substantial improvement of working conditions. It compacts itself due to its self-weight and is de-aerated almost completely while flowing into the formwork. Thus, the two main properties specific to fresh SCC are its filling-ability and passing ability. In this paper, different mixes of SCC were prepared and these fresh properties were investigated through V-funnel and L-box test, respectively. Also the compressive strength of hardened SCC cubes was measured after specified days of curing $(7,14,28,60 \& 90$ days). Furthermore, the durability properties, like Surface absorption and Permeability, were determined by Initial Surface Absorption Test (ISAT) and Capillary Suction Test, respectively.
\end{abstract}

Keywords: Durability; Fly Ash; Metakaolin; Self-Cmpacting Cocncrete, ISAT

\section{INTRODUCTION}

Cementitious materials are the most abundant of all man-made materials and are among the most important construction materials, and it is most likely that they will continue to have the same importance in the future. However, these construction and engineering materials must meet new and higher demands. Sustainability is important to the well-being of our planet, continued growth of a society, and human development. A sustainable concrete structure is constructed to ensure that the total environmental impact during its life cycle, including its use, will be minimal. Sustainable concrete should have a very low inherent energy requirement, be produced with little waste, be made from some of the most plentiful resources on earth, produce durable structures, have a very high thermal mass, and be made with recycled materials. Sustainable constructions have a small impact on the environment. One direction in this evolution is towards SCC, a modified product that, without any additional compaction energy, flows and consolidates under the influence of its own weight.

\footnotetext{
* Corresponding author. Tel.: ++91 9876497242

E-mail address: rizwankhan1@gmail.com (R.A. Khan)
} 
With regard to its composition, SCC is a sensitive mix, strongly dependent on the composition and characteristics of its constituents. It consists of the same components as of conventionally vibrated concrete, which are cement, aggregates and water, with the addition of chemical and mineral admixtures in different proportions. Usually, the chemical admixtures used are high-range water reducers (super plasticizers) and viscosity-modifying agents, which change the rheological properties of concrete. Mineral admixtures are used as extra fine materials, besides cement, and in some cases they replace cement.

The two main properties specific to fresh SCC are its filling-ability and passing ability. Different mixes of SCC were prepared and these fresh properties were investigated through V-funnel and L-box test, respectively. Also the compressive strength of hardened SCC cubes was measured after specified days of curing $(7,14,28,60 \& 90$ days). Furthermore, the durability properties, like Surface absorption and Permeability, were determined by Initial Surface Absorption Test (ISAT) and Capillary Suction Test, respectively.

Mineral admixtures are added to concrete as part of the total cementitious system. They may be used in addition to or as a partial replacement of Portland cement in concrete depending on the properties of the materials and the desired effect on concrete. Mineral admixtures are used to improve a particular concrete property such as workability, strength or compact ability.

Chemical admixtures represent those ingredients which can be added to the concrete mixture immediately before or during mixing. The use of chemical admixtures such as water reducers, retarders, high-range water reducers or super-plasticizers (SP) and viscosity-modifying admixtures is necessary in order to improve some fundamental characteristics of fresh and hardened concrete. They make more efficient use of the large amount of cementitious material in high strength and self-compacting concretes and help to obtain the lowest practical water to cementing materials ratio.

The widespread research and development of SCC in the past two decades has led to a substantial and increasing number of publications of all types. Investigations done by various researchers in the field of SCC, the effect of different binders, filler materials and waste materials on the fresh, hardened and durability properties of self compacting concrete was studied and reviewed. Some of them were:

The influence of Fly Ash (FA) content in SCC on the early age properties, workability, compressive strength, ultrasonic pulse velocity, absorption \& shrinkage was studied by Sukumar et al. [23], Khatib [15], Liu [19] , Khanand Sharma[18], Mithun and Narsimhan[21] \& Poon and Ho [22]. It was found that FA was technically feasible to be utilized in SCC \& besides environmental benefits, there were technical and financial benefits as well such as high workability, high compressive strength upto $20 \%$ replacement of cement by FA \& increased sorptivity with FA content between 60-80\% .

The role of metakaolin (MK) on the strength, water absorption, permeability, fresh and hardened properties \& its fineness \& content in SCC was studied by Wild et al. [28], Khatib and Clay [14], Khatib and Hibbert [17], Melo and Carneiro [20], Thanh and Ludwig[25], Vejmelkova et al. [26] \& Güneyisi et al [13]. It was found that 20\% MK content gave long term strength, decrease in water absorption by capillary action \& higher permeability resistance. The compressive strength of SCC also decreased with the increase in the Metakaolin amount and with the reduction of its finesses.

The effect of super plasticizers (SP), curing conditions \& water-to-cement (w/c) ratio on the rheological parameters and the properties of the concrete was carried out by Faroug et al. [12], Aruntas et al. [10]. It was found that introduction of super plasticizers into concrete mixes improved their workability by lowering the shear and flow resistance. The slump value and flexural strengths of concrete increased whereas the compressive strength decreased, as compared to control concrete on increasing the SP in the concrete. This paper focuses on the fresh, hardened \& durability properties of SCC replacing cement by the mineral admixtures such as fly ash \& metakaolin and summarizes the outcomes of the research carried out at the National Institute of Technology, Jalandhar. 


\section{Experimental Setup}

The concrete mix proportion used in this investigation for casting the test specimens is shown in Table- 1 . An extensive experimental program was conducted which included evaluation of fresh properties, compressive strength, split tensile strength and durability properties of different SCC specimens having different combinations of binders. The various materials used during the experiment in formulation of SCC were OPC 43 grade cement, sand made of crushed aggregates as fine aggregates, locally available crushed stone aggregates of $12.5 \mathrm{~mm}$ nominal maximum size as coarse aggregates, Class-F fly ash from Guru Gobind Singh super thermal plant Ropar, Metakaolin named Metacem 85C, super-plasticizer (SP) of Modified Poly-carboxylates type named Sika Viscocrete 20-HE manufactured by Sika \& potable water free from acidic and alkaline matter. The materials conformed to the relevant Indian Standard Specifications. The specimen used for compressive strength and permeability tests were $150 \times 150$ x $150 \mathrm{~mm}$ cubes whereas 3 cylinders for sorption tests of $100 \mathrm{~mm}$ diameter \& 200mm height were cast. Appropriate dose of super plasticizer was used to maintain workability. Out of each batch of concrete, eight cubes were tested in compressive strength and the remaining seven specimens were left for carrying out permeability \& sorption tests.

The compressive strength tests were conducted on concrete cubes in a $2000 \mathrm{kN}$ Universal Testing Machine. The load was applied at a rate of $3.5 \mathrm{~N} / \mathrm{mm}^{2} / \mathrm{min}$ and the average of two samples was taken as the representative value of compression strength for each batch of SCC. The durability properties of SCC were checked by Initial Surface Absorption Test (ISAT) to provide data for assessing the uniaxial water penetration characteristics on the cubes after curing age of 28 and 60 days as per BS 1881-208 [2] . The Capillary Suction Test was performed on the standard test specimen of $100 \pm 6 \mathrm{~mm}$ diameter disc, with a length of $50 \pm 3 \mathrm{~mm}$ as per ASTM standard C 1585-04 [1] Standard Test Method for Measurement of Rate of Absorption of Water by Hydraulic- Cement Concretes to determine the rate of absorption (sorptivity) of water by SCC by measuring the increase in the mass of a specimen resulting from absorption of water as a function of time when only one surface of the specimen is exposed to water. Various tests such as Slump Flow test, J Ring test, L - Box test \& V - Funnel test for testing the fresh properties of SCC were also carried out \& the results obtained were as per EFNARC [3] standards.

Table 1. Mix Design proportion in $\mathrm{kg} / \mathrm{m}^{3}$

\begin{tabular}{ccccc}
\hline Binders & Fine Aggregates & Coarse Aggregates & Water & SP Dosage \\
\hline 600 & 882 & 530 & 246 & 4.20 \\
\hline
\end{tabular}

Three different combinations of binders were prepared keeping all other parameters constant. Those combinations are as follows (Table 2):

Table 2. Combinations of Binders

\begin{tabular}{cccc}
\hline S. No. & OPC (\%) & Fly Ash (\%) & Metakaolin (\%) \\
\hline 1 & 70 & 30 & 0 \\
2 & 70 & 25 & 5 \\
3 & 70 & 20 & 10 \\
\hline
\end{tabular}

The sand, coarse aggregates, water/binder ratio and Super-plasticizer dosage were kept constant throughout all the 3 mixes. The mix proportions in $\mathrm{kg} / \mathrm{m}^{3}$ of all the mixes used in the experiments are given as follows (Table 3): 
Table 3. Mix Proportions of all mixes in $\mathrm{kg} / \mathrm{m} 3$

\begin{tabular}{cccccccc}
\hline $\begin{array}{c}\text { Mix } \\
\text { Id }\end{array}$ & Cement & $\begin{array}{c}\text { Fly ash } \\
\text { (FA) }\end{array}$ & $\begin{array}{c}\text { Metakaolin } \\
\text { (MK) }\end{array}$ & Sand & $\begin{array}{c}\text { Coarse } \\
\text { aggregate }\end{array}$ & $\begin{array}{c}\text { W/B } \\
\text { ratio }\end{array}$ & SP \\
\hline M1 & 420 & 180 & 0 & 882 & 530 & 0.41 & 4.20 \\
M2 & 420 & 150 & 30 & 882 & 530 & 0.41 & 4.20 \\
M3 & 420 & 120 & 60 & 882 & 530 & 0.41 & 4.20 \\
\hline
\end{tabular}

\section{Results and Discussions}

\subsection{Workability Test Results}

All the mixes are found to be within the specified limits permissible for SCC at a constant water-binder ratio of 0.41 and constant super plasticizer dosage of $1 \%$ by weight of cement $\&$ are according to EFNARC standards. For each of the three mixes, the obtained values for testing of fresh properties are:

Table 4. Fresh properties test results for all SCC mixes

\begin{tabular}{ccccc}
\hline Mix ID & Slump Flow dia. $(\mathbf{m m})$ & J-ring $(\mathbf{m m})$ & V-Funnel Time (sec) & $\begin{array}{c}\text { L-box } \\
\left(\mathbf{H}_{2} / \mathbf{H}_{\mathbf{1}}\right)\end{array}$ \\
\hline M1 & 780 & 6 & 6.1 & 1.0 \\
M2 & 690 & 7 & 6.8 & 0.94 \\
M3 & 670 & 8 & 7.8 & 0.93 \\
\hline
\end{tabular}

\subsection{Compressive Strength Test Results}

The results of the compressive strength test conducted on SCC containing different combinations of FA \& MK are presented in Table-5 and Fig.-1.The general trend of strength variation of all the 3 mixes is shown in Fig.1. It is observed that compressive strength increases as the fly ash is replaced by $5 \%$ metakaolin resulting in approximately $52.37 \%, 21.34 \%, 32.75 \%$ and $30.51 \%$. The mix M1 having 30\% fly ash shows the least compressive strength and the mix M3 having 20\% fly ash and 10\% metakaolin shows the highest compressive strength at all curing ages. However it is seen that the mix M3 having 20\% FA and 10\% MK has highest compressive strength i.e. 46.2 MPa at 60 days of curing. In general, the density tends to increase slightly with increasing amounts of MK in concrete, mainly resulting from the filling effects of MK particles as also reported by Khatib (2008).

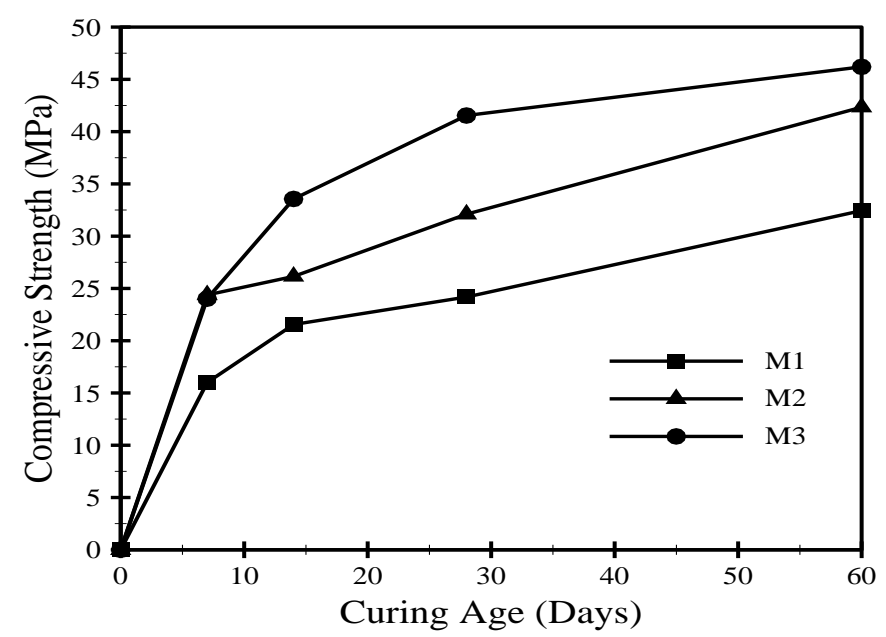

Fig. 1. Compressive Strength of different mixes at 7, 14, $28 \& 60$ days 
Table 5. Compressive strength test results at different curing ages

\begin{tabular}{cccccc}
\hline \multirow{2}{*}{ Mix no. } & Description & \multicolumn{4}{c}{ Compressive strength (MPa) } \\
\cline { 3 - 6 } 1 & $70 \%$ OPC 30\%FA & 16.00 & 21.55 & 24.18 & 32.44 \\
2 & $70 \%$ OPC 25\%FA 5\%MK & 24.38 & 26.15 & 32.10 & 42.34 \\
3 & $70 \%$ OPC 20\%FA 10\%MK & 24.02 & 33.56 & 41.54 & 46.20 \\
\hline
\end{tabular}

\subsection{Durability Test Results}

Durability of hardened SCC is determined by conducting Initial Surface Absorption Test (ISAT) for permeability and Capillary Suction test for sorption.

\subsection{Permeability Test Results}

The results and the inferences drawn from the test are presented in this section. The ISAT test results for SCC containing different combinations of FA \& MK for 10 minutes are compared in Fig. -2 for 28 and 60 days.

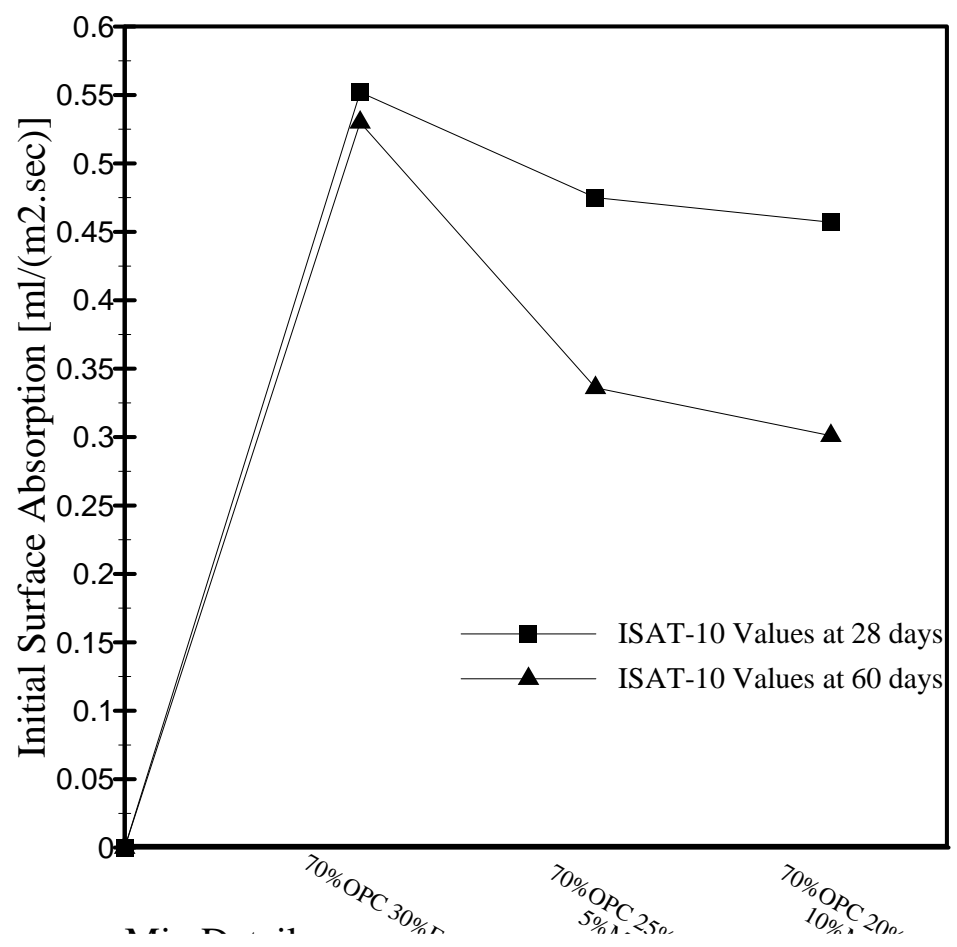

Fig. 2 ISAT-10 values of different mixes at 28 and 60 days of curing

The ISAT values (10 min) of SCC mixes at different curing ages are represented in Table 6. 
Table 6. ISAT-10 values of different mixes at 28 and 60 days of curing

\begin{tabular}{|c|c|c|c|}
\hline \multirow{3}{*}{ Mix no. } & \multirow{3}{*}{ Description } & \multicolumn{2}{|c|}{ Initial Surface Absorption $\left[\mathrm{ml} /\left(\mathrm{m}^{2} . \mathrm{sec}\right)\right]$} \\
\hline & & 28D & 60D \\
\hline & & 10 Min & 10 Min \\
\hline 1 & $70 \%$ OPC $30 \% \mathrm{FA}$ & 0.552 & 0.530 \\
\hline 2 & 70\%OPC 25\%FA 5\%MK & 0.475 & 0.336 \\
\hline 3 & 70\%OPC 20\%FA 10\%MK & 0.457 & 0.301 \\
\hline
\end{tabular}

It is observed that the ISAT -10 values at 60 days are less than ISAT -10 values at 28 days for all mixes \& mix M3 having 20\% fly ash and 10\% metakaolin has the least value i.e. $0.301 \mathrm{ml} / \mathrm{m}^{2} . \mathrm{sec}$ at 60 days of curing. It is seen that mixes M2 and M3 having 5\% \& 10\% replacement of fly ash by metakaolin, respectively, show a decrease in the ISAT values at 28 day curing. Mix M6 shows the least ISAT-10 value.

\subsection{Sorptivity Test Results}

Capillary suction test was conducted on standard test specimen of different mixes after 28 and 60 days of curing to check the sorptivity of SCC. It was noticed that for all the three specimens tested, the relationship between cumulative water absorption and the square root of time of exposure begins to deviate from linearity after about 360 minutes (6 hours). Therefore, it was decided to base the calculations on the first 6 hours of elapsed test time which will give the initial rate of absorption (IRA). IRA $\left(\mathrm{mm} / \mathrm{sec}^{1 / 2}\right)$ is defined as the slope of the line that is the best fit to absorption (I) plotted against the square root of time $\left(\sec ^{1 / 2}\right)$. Table 7 shows average IRA values of different SCC specimens at 28 and 60 days of curing.

Table 7. IRA values of different mixes at 28 and 60 days of curing

\begin{tabular}{cccc}
\hline \multirow{2}{*}{ Mix no. } & Description & \multicolumn{2}{c}{ Average IRA (mm/sec $\left.\mathbf{s}^{\mathbf{1}}\right)$} \\
\cline { 3 - 4 } 1 & $70 \%$ OPC 30\%FA & 28D & 0.0200 \\
2 & $70 \%$ OPC 25\%FA 5\%MK & 0.0153 & 0.0107 \\
3 & $70 \%$ OPC 20\%FA 10\%MK & 0.0083 & 0.0077 \\
\hline
\end{tabular}

It was observed that the IRA values decreased significantly when the amount of FA was reduced and was replaced by MK dropping by $24.63 \%$ \& $59.11 \%$ at 28 days and by $46.5 \%$ \& $61.5 \%$ at 60 days of curing, on replacing FA by $5 \%$ \& $10 \%$ MK respectively. The mix M3 having 10\% MK replacement has the least average IRA value i.e. 0.0077 . The use of MK appeared to be much more effective in reducing the sorptivity due to the reduced pore volume as also reported by Guneyisi et al. (2011). 


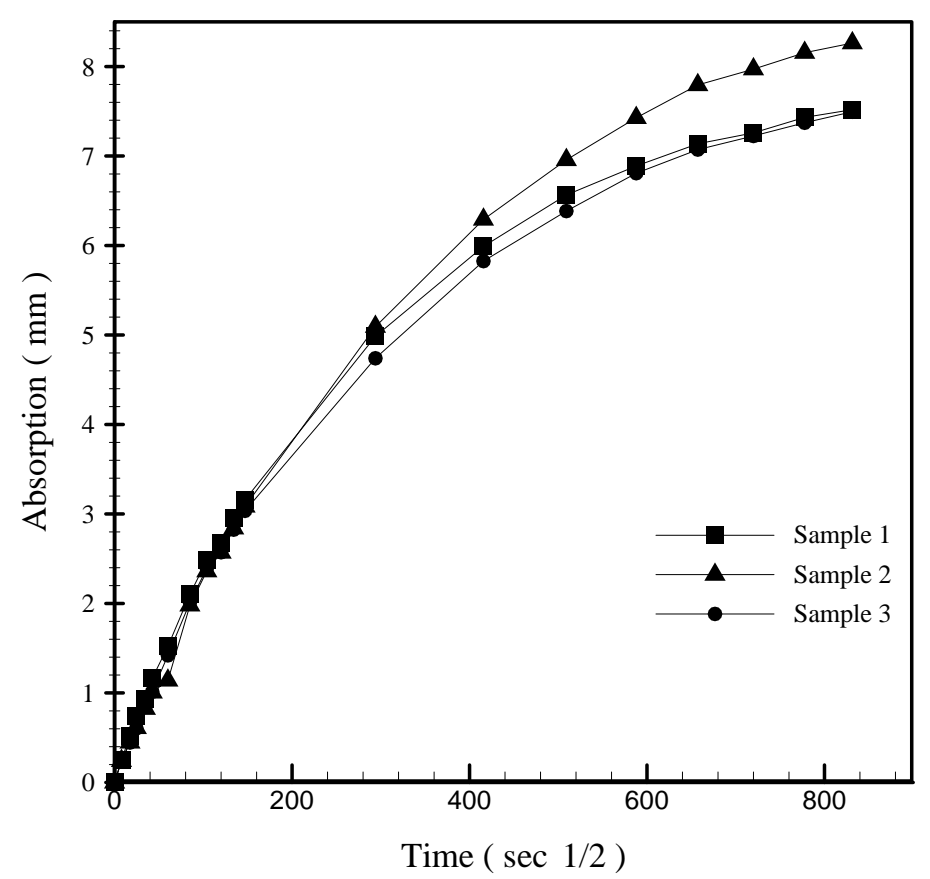

Fig. 3 Absorption values for mix M1 at 28 days ofcuring

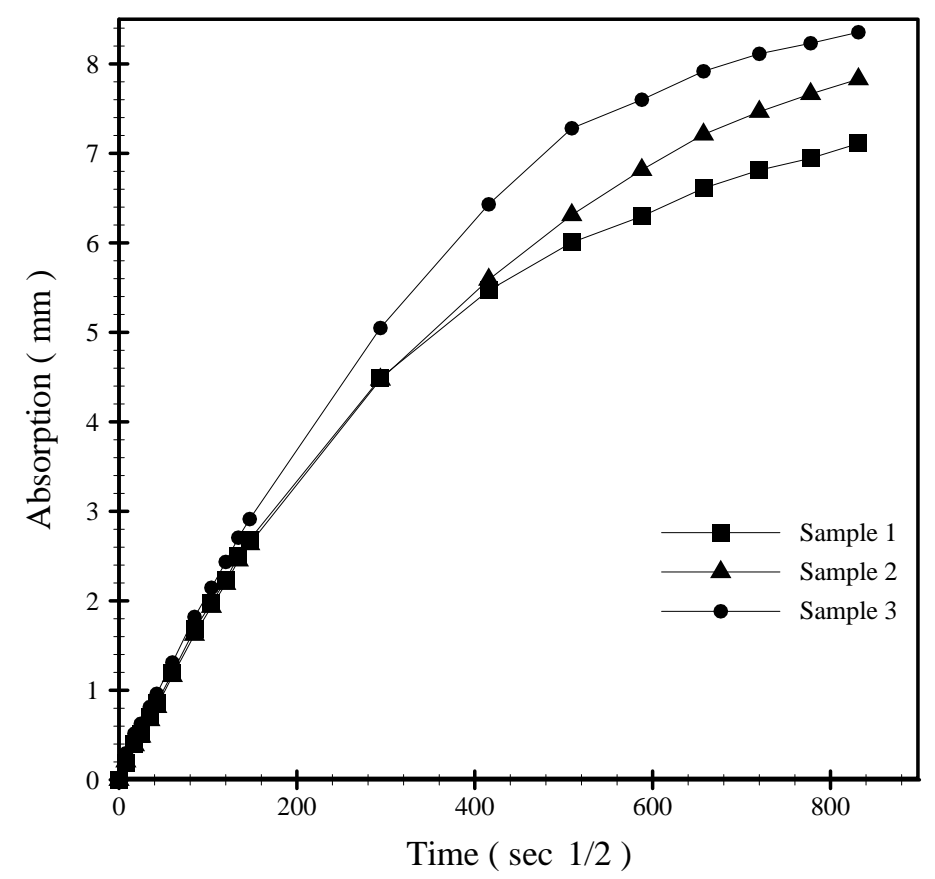

Fig. 4 Absorption values for mix M2 at 28 days of curing 


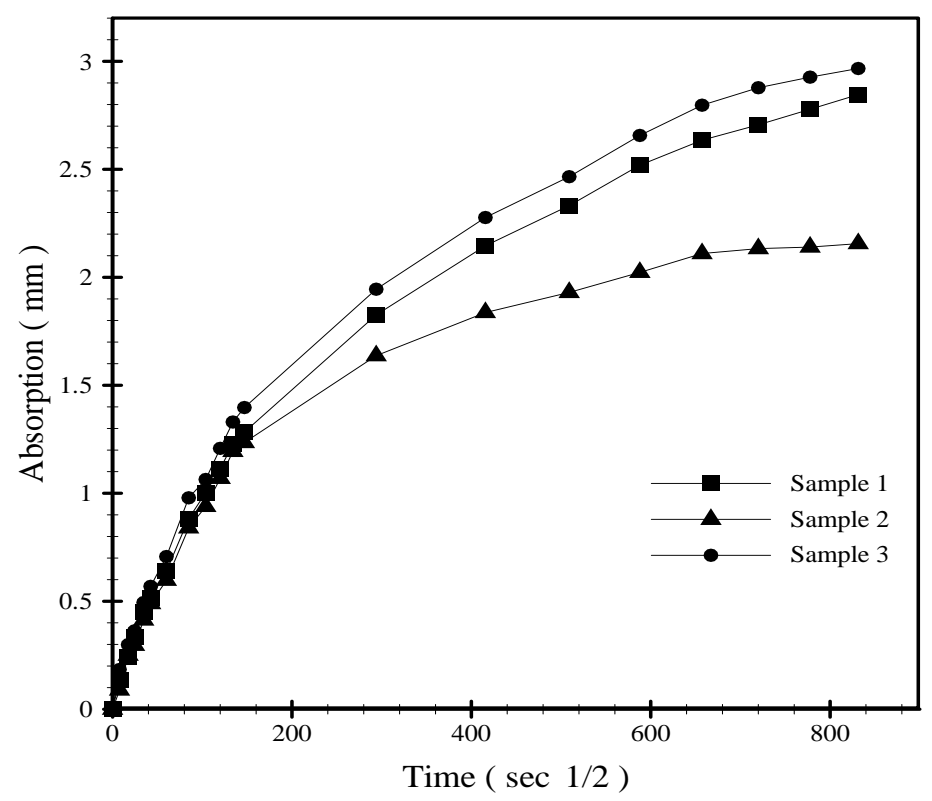

Fig. 5 Absorption values for mix M3 at 28 days of curing

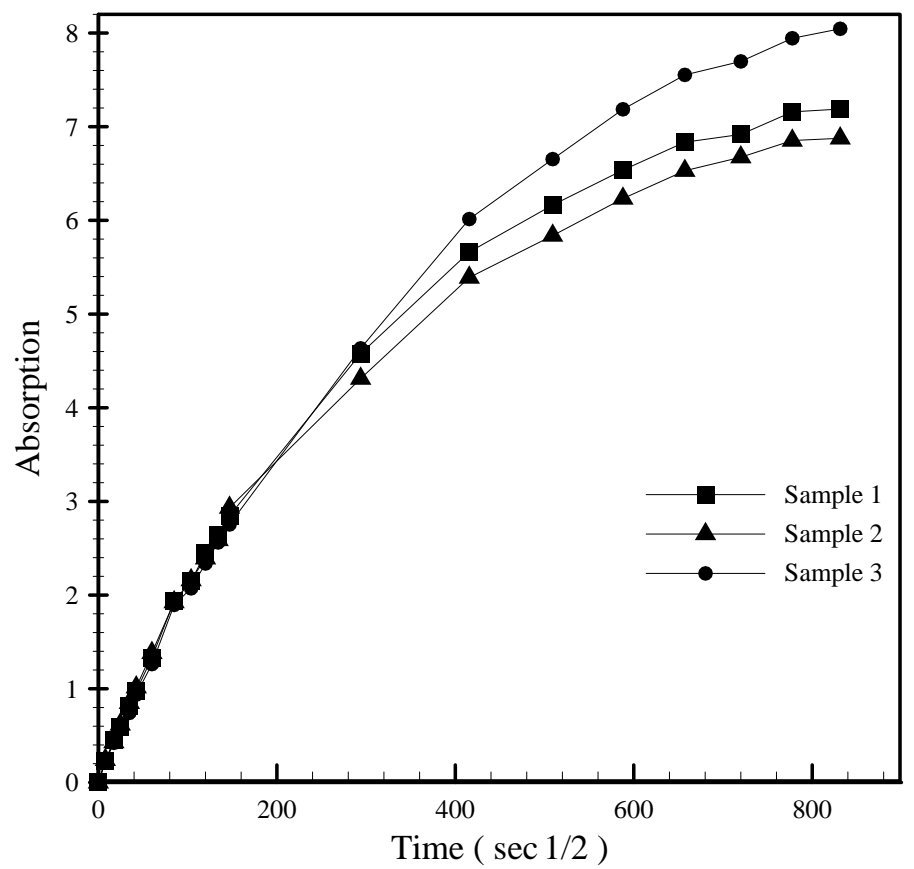

Fig. 6 Absorption values for mix M1 at 60 days of curing 


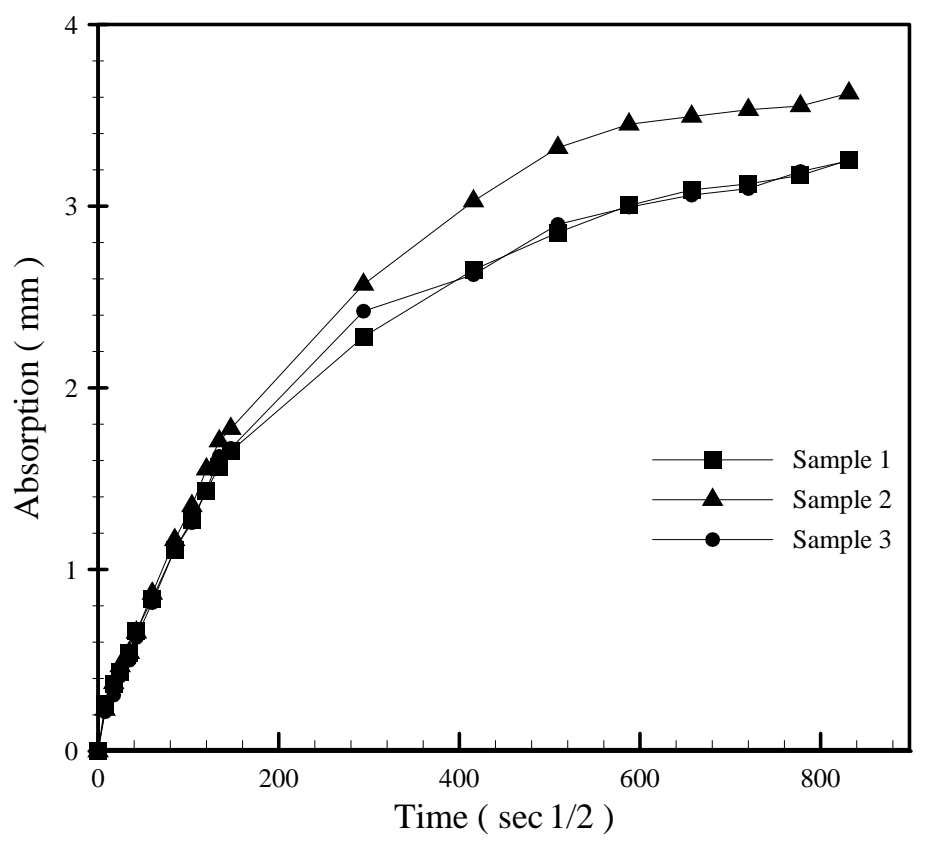

Fig. 7 Absorption values for mix M 2 at 60 days of curing

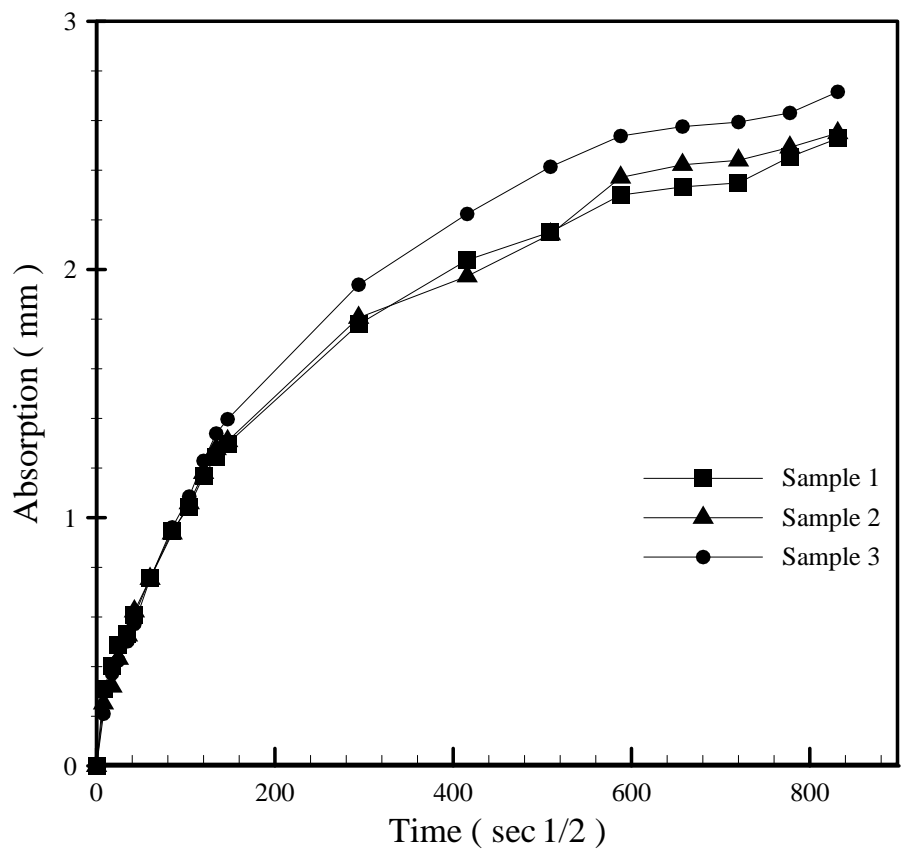

Fig. 8 Absorption values for mix M 3 at 60 days of curing 


\section{CONCLUSION}

Properties, such as compressive strength, absorption and permeation of SCC containing different combinations of FA and MK have been investigated. SCC mixes containing different replacement levels of different admixtures were found to comply with all the workability requirements as per EFNARC (2005) \& the mixes had good workability and consistency at a constant $w / b$ ratio of 0.41 and constant SP dosage of $1.0 \%$ of weight of cement. The comparison of workability test values of mixes shows that as fly ash is replaced by increasing percentages of MK, the mixes become dense and hence less workable which is because MK is finer than FA. The compressive strength showed an increase with increasing percentage replacement of fly ash with metakaolin. The mix M3 having 10\% replacement of fly ash with metakaolin has highest compressive strength than all mixes at all ages of curing. This is because of increase in density resulting from the filling effect of MK particles. ISAT value showed a decrease with period and curing for all mixes. Mix with $10 \%$ metakaolin addition was found to have lower ISAT - 10 values than mix with its 5\% addition. Metakaolin addition showed the least value of ISAT - 10 at all curing ages. Sorptivity decreased with increase in curing age from 28 to 60 days for all mixes. The mix M3 had least value of IRA at both curing ages. This is due to the reduction in pore volume. Good co-relation between strength and absorption properties of concrete was found. With increase in strength, initial surface absorption and sorptivity values were found to decrease. It can be thus safely concluded from the results that SCC mix containing 10\% metakaolin is the most appropriate mix for compressive strength, initial surface absorption and capillary suction taken together. Future studies such as carbonation resistance, electrical resistivity can be taken up to understand the durability aspect of the present study. The effect of water binder ratios on the strength and durability properties can also be studied.

\section{REFERENCES}

1. ASTM Standard C 1585 - 04 'Standard Test Method for Measurement of Rate of Absorption of Water by Hydraulic - Cement Concretes'. ASTM International.

2. BS 1881-208 'Testing concrete - Part 208: Recommendations for the determination of the initial surface absorption of concrete' 1996.

3. EFNARC "The European Guidelines for Self-Compacting Concrete” 2005.

4. IS: 383 "Indian Standard specification for coarse and fine aggregates from natural sources for concrete". Bureau of Indian Standards, New Delhi, 1970.

5. IS: 456 "Indian Standard Plain and Reinforced Concrete-Code of Practice (Fourth Revision)". Bureau of Indian Standards, New Delhi, 2000.

6. IS: 516 "Methods of Test for Strength of Concrete". Bureau of Indian Standards, New Delhi, 1959.

7. IS: 2430 "Indian Standard methods for sampling of aggregates for concrete". Bureau of Indian Standards, New Delhi, 1986.

8. IS: 8112 “Indian Standard 43 grade Ordinary Portland Cement Specification”. Bureau of Indian Standards, New Delhi, 1989.

9. IS: 9103 "Indian standard concrete admixtures - specification". Bureau of Indian Standards, New Delhi, 1999.

10. Aruntas H. Y., Cemalgil S., Şimsek O., Durmus G. And Erdal M. 'Effects of super plasticizer and curing conditions on properties of concrete with and without fiber'. Materials Letters, 62, 3441-3443, 2008.

11. Bonavetti V., Donza H., Rahhal V. And Irassar E. 'Influence of initial curing on the properties of concrete containing limestone blended cement'. Cement and Concrete Research, 30, pg. 703-708, 2000.

12. Faroug F., Szwabowski J. And Wild S. 'Influence of Superplasticizers on Workability of Concrete'. Journal of Materials in Civil Engineering, 1999.

13. Guneyisi E., Gesoglu M. And Özbay E. 'Permeation Properties of Self-Consolidating Concretes with Mineral Admixtures'. ACI Materials Journal, 2011.

14. Khatib J. M. And Clay R. M. 'Absorption characteristics of metakaolin concrete'. Cement and Concrete Research, doi:10.1016/S0008-8846(03)00188-1, 2003.

15. Khatib J.M. 'Metakaolin concrete at a low water to binder ratio'. Construction and Building Materials, 22, 1691-1700, 2008. 
16. Khatib J.M. 'Performance of self-compacting concrete containing fly ash'. Construction and Building Materials, 22, 1963-1971, 2008.

17. Khatib J.M. And Hibbert J.J. 'Selected engineering properties of concrete incorporating slag and metakaolin'. Construction and Building Materials, 19, 460-472, 2005.

18. Khan, R.A., Sharma, A., 2015. Durability Properties of Self Compacting Concrete containing Fly ash, Lime powder and Metakaolin. J. Mater. Eng. Struct. 2, 206-212.

19. Liu M. 'Self-compacting concrete with different levels of pulverized fuel ash'. Construction and Building Materials, 24, 1245-1252, 2010.

20. Melo K. A., Carneiro A. M. P. 'Effect of Metakaolin's finesses and content in self-consolidating concrete'. Construction and Building Materials, 24, 1529-1535, 2010.

21. Mithun, B.M., Narasimhan, M.C., 2016. Performance of alkali activated slag concrete mixes incorporating copper slag as fine aggregate. J. Clean. Prod. 112, 837-844. doi:10.1016/j.jclepro.2015.06.026

22. Poon C. S. And Ho D. W. S. 'A feasibility study on the utilization of r-FA in SCC'. Cement and Concrete Research, 34, 2337-2339, 2004.

23. Sukumar B., Nagamani K. And Raghavan R. S. 'Evaluation of strength at early ages of self-compacting concrete with high volume fly ash'. Construction and Building Materials, 22, 1394-1401, 2008.

24. Testing-SCC "Guidelines for testing fresh self-compacting concrete". European Research Project, 2005.

25. Thanh, H., Ludwig, H., 2016. Effect of rice husk ash and other mineral admixtures on properties of selfcompacting high performance concrete. Mater. Des. 89, 156-166. doi:10.1016/j.matdes.2015.09.120

26. Vejmelkova E., Keppert M., Grzeszczyk S., Skalinski B. And Cerny R. 'Properties of self-compacting concrete mixtures containing metakaolin and blast furnace slag'. Construction and Building Materials, doi:10.1016/j.conbuildmat.2010.09.012, 2010.

27. Vejmelkova E., Pavlikova M., Keppert M., Kernesnr Z., Rovnanikova P., OondracEk M., Sedlmajer M. And C`Erny R. "High performance concrete with Czech metakaolin: Experimental analysis of strength, toughness and durability characteristics". Construction and Building Materials, 24, 1404-1411, 2010.

28. Wild S., Khatib J.M. And Jones A. 'Relative Strength, Pozzolanic Activity and Cement Hydration in Superplasticised Metakaolin Concrete'. Cement and Concrete Research, Vol. 26, No. 10, pp. 1537-1544, 1996. 